Available online on 15.09 .2017 at http://iddtonline.info
Journal of Drug Delivery and Therapeutics
Open Access to Pharmaceutical and Medical Research
$\begin{gathered}\text { C 2011-17, publisher and licensee JDDT, This is an Open Access article which permits unrestricted non- } \\ \text { commercial use, provided the original work is properly cited }\end{gathered}$

Open $\odot$ Access

Review Article

\title{
SUPERCRITICAL FLUID TECHNOLOGY: AN INNOVATIVE APPROACH USED TO ENHANCE SOLUBILITY OF WATER INSOLUBLE DRUGS
}

\author{
Kaur Taranjit ${ }^{1}$, Sharma Prachi ${ }^{1}$, Kumar Sandeep ${ }^{2}$ \\ ${ }^{1}$ Department of Pharmaceutics, St. Soldier Institute of Pharmacy, Jalandhar, (Pb.), India \\ ${ }^{2}$ ASBASJSM College of pharmacy, Bela, Ropar ( $\mathrm{Pb}$.), India
}

\section{ABSTRACT}

Certain techniques are used for the preparation of solid dispersions and used to enhance the solubility of water insoluble drugs. One of its techniques is supercritical fluid technology that is used for the preparation of solid dispersions. The present aim of this technique is to provide the recent advances in the use of supercritical fluids for the preparation of solid dispersion and for pharmaceutical substances with particular attention to drug delivery systems. Basically a "supercritical fluid" can be defined as it enters in the pure substance when both temp. \& pressure above its critical P\&T. In the SCF techniques there are certain solvents like $\mathrm{CO}_{2}, \mathrm{~N}_{2} \mathrm{O}$ used as supercritical fluid. This innovative technique is highly promising and approachable for the future applications in pharmaceutical industries.

Keywords: Supercritical fluids, solubility, solid dispersion, drug delivery and Applications.

Article Info: Received 20 July, 2017; Review Completed 03 Sep, 2017; Accepted 04 Sep, 2017; Available online 15 Sep, 2017

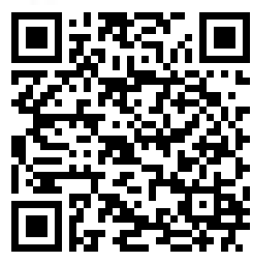

*Address for Correspondence

Taranjit Kaur, Department of Pharmaceutics, St. Soldier Institute of Pharmacy, Jalandhar, (Pb.), India

Cite this article as:

Kaur T, Sharma P, Kumar S, Supercritical fluid technology: an innovative approach used to enhance solubility of water insoluble drugs, Journal of Drug Delivery and Therapeutics. 2017; 7(5):22-26

DOI: http://dx.doi.org/10.22270/jddt.v7i5.1495

\section{INTRODUCTION}

There are number of approaches can be used to enhance the solubility of poorly soluble drugs such as Solid dispersion $^{1}$, hydration, Nanosuspension ${ }^{2}$, lipid based drug delivery systems ${ }^{3}$ and Cocrystalization ${ }^{4}$. Apart from available approaches of supercritical fluid technology is an emerging alternative approach for enhancement of solubility of such drugs.

In the pharmaceutical field, early 1980s; Supercritical fluid technology was applied for industrial applications in the same period. This is a recent technique that produces fine drug particles and becomes more valuable for product quality, batch consistency and useful for the pharmaceutical applications. The progress in this technology is based on multidisciplinary approach and a considerable progress has been made over the last decade in the application of supercritical fluids (SCFs) to the processing of pharmaceuticals ${ }^{5,6}$ and to the preparation of drug delivery systems ${ }^{7,8}$. The use of SCFs for the preparation and control of the specific physical form of pharmaceutical substances relevant to those fluids used for drug delivery systems have been described $^{9,10}$. SCFs are also having various applications in the food industry and pharmaceutical industry especially in the drug delivery system designs that becomes more recent technique for the future perspectives of pharmaceutical applications. Basically the original concept of supercritical fluids as becomes "green" alternative approach and very important as the regulatory requirements and residual contents of volatile solvents in the drug products that becomes more restrictive.

\section{Supercritical fluids:}

Critical temperature: The critical temperature of a supercritical fluid may be defined as, at highest temperature of the gas which can be liquefied by raising the pressure of the system. 
Critical pressure: The critical pressure of supercritical fluid may be defined as, at highest pressure a liquid becomes converted to the gas by raising the temperature of the system.

A supercritical fluid can defined as any substance at a temp. \& pressure above its critical point where the liquid and gas phase can co exist and at this stage it is called Supercritical fluid, while this technique utilizing these fluids, then it is called as Supercritical fluid technology 9 . In this region, the SCF exists as in an intermediate phase between liquid and gas phases ${ }^{9}$. The typical operating conditions for critical temperature and pressure for supercritical fluids are $1.01(\mathrm{Tc})$ to $1.1(\mathrm{Tc})$ and $1.01(\mathrm{Pc})$ to $1.1(\mathrm{Pc})$, respectively. At this critical point only a single phase can exist which has some typical properties of liquids and gases (viscosity, compressibility and diffusion coefficient).

Advantages of supercritical fluid technology and becomes more effective over other techniques are ${ }^{11}$ :

1. Supercritical fluids are highly versatile $\&$ flexible.

2. Supercritical fluids are used with the less amount of organic solvents ability to reach the desired conditions (change in pressure $\&$ the rate of solvent evaporation).
3. This processes shows high compressibility \&diffusivity of the supercritical fluids.

4. Supercritical fluid technology is used to enhance the selectivity and yield by adjusting the solvent strength.

5. SCF has High diffusion coefficient and low viscosity.

6. Good environment compatibility and non toxicity of the solvents.

Certain commonly used supercritical solvents are: carbon dioxide, nitrous oxide, ethylene, propylene, propane, n-pentane, ethanol, ammonia, and water. Carbon dioxide is most commonly used because it has low critical temperature $(\mathrm{Tc}=31.10 \mathrm{C})$ and pressure $(\mathrm{Pc}$ $=73.8$ bar) and becomes more advantageous i.e. nontoxic, non-flammable, and inexpensive, and low critical temperatures ${ }^{14}$.This process is useful for processing of heat labile molecules by proper adjustments of operating conditions as well as physical and chemical parameters (pressure, temperature, drug concentration, flow and nature of supercritical fluid and organic solvents) ${ }^{9}$.

Some common Supercritical solvents used in the industry $\operatorname{are}^{12}$ :

\begin{tabular}{|l|l|l|l|}
\hline Solvent & Critical Pressure (Atm) & Critical temperature (K) & Density (mg/ml) \\
\hline $\mathrm{H}_{2} \mathrm{O}$ & 218 & 647 & 320 \\
\hline $\mathrm{CO}_{2}$ & 73 & 304 & 470 \\
\hline $\mathrm{C}_{2} \mathrm{H}_{5} \mathrm{OH}$ & 63 & 517 & 280 \\
\hline $\mathrm{C}_{6} \mathrm{H}_{6}$ & 48 & 562 & 300 \\
\hline $\mathrm{NH}_{3}$ & 113 & 406 & 240 \\
\hline $\mathrm{C}_{2} \mathrm{H}_{6}$ & 48 & 306 & 600 \\
\hline $\mathrm{CHCl}_{3}$ & 28 & 209 & 340 \\
\hline
\end{tabular}

Supercritical fluids are also having moderate to high density around the supercritical region also shows high compressibility. Even, if it shows slight variation in the applied pressure then it may causes alteration in its density and solvency of the organic solvent. The solvency power of the supercritical fluids that compares with gases and liquids on the basis of their density and viscosity ${ }^{11,13}$.

Properties of Supercritical Fluid that compares with Gas \& water on the basis of their density and viscosity ${ }^{11}$

\begin{tabular}{|l|l|l|l|l|}
\hline $\begin{array}{l}\text { Phase of the } \\
\text { Solvent }\end{array}$ & $\begin{array}{l}\text { Density } \\
\text { (gm/ml) }\end{array}$ & $\begin{array}{l}\text { Viscosity } \\
\text { (gm.cm-1 sec-1) }\end{array}$ & $\begin{array}{l}\text { Coefficient of } \\
\text { diffusion }\end{array}$ & Comparison \\
\hline Super critical Fluid & 0.1 to 1.0 & 0.0001 to 0.001 & 0.001 to 0.0001 & Viscosity is similar to gas. \\
\hline Gaseous & 0.001 & 0.0001 & 0.1 & $\begin{array}{l}\text { Viscosity is similar to supercritical } \\
\text { fluid }\end{array}$ \\
\hline Liquid & 1.0 & 0.01 & Less than 0.00001 & $\begin{array}{l}\text { Viscosity is greater than Gas and } \\
\text { supercritical fluid }\end{array}$ \\
\hline
\end{tabular}

\section{General phase diagram of super critical fluid region:}

If any fluid said to be entered in the supercritical phase region, at which both pressure and temperature crosses its critical pressure and temperature values, during these conditions, the Supercritical fluid depicts its existence in an intermediate phase between gaseous and liquid phases respectively ${ }^{14}$.

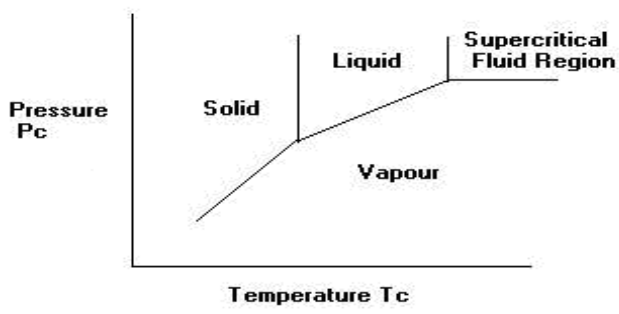




\section{Classification of supercritical fluids ${ }^{11}$ :}

\section{Technologies using SCF as a Solvent:}

RESS (Rapid Expansion of Supercritical Solution).

$>$ RESOLV (Rapid Expansion Using SCF As A Solvent Into A Liquid Solvent)

2. Technologies using SCF as an anti-solvent:

GAS(Gaseous Anti-solvent)

$>$ PCA (Particles by Compressed Anti-solvent), SAS (Supercritical Anti-solvent), ASES (Aerosol Solvent Extraction System).

SEDS (Solution Enhanced Dispersion into a liquid Solvent.

Some technologies used in the Supercritical Fluid technology: In Super critical fluid technology, it becomes possible:

$>$ To reduce the size of the particle.

$>$ The content of the residue of the solvent in single step and control the various parameters related to the particle characteristics like particle size distribution, polymorphism, crystal lattice and morphology.

We can classify the processes in two groups as depending on the use of the supercritical fluid in the system:
A.) Solvent
B.) Anti-solvent.

Technologies using SCF as a solvent:

1. RESS (Rapid expansion of a supercritical solution):

This technology was firstly recorded by Hannay and Hogarth $^{9}$

$>$ Simple process.

> Supercritical fluid is used as a crystallization solvent.

$>$ Solution is rapidly expanded by sudden decompression passing through an orifice at reduced pressure.

When the solid is dissolved in the gas and then the solid is precipitated by reducing the pressure then it becomes brought as a snow in the gas. Firstly this concept is applied to produce fine particles with narrow range size distribution using SCF technology and this technique called as rapid expansion of a supercritical solution $(\mathrm{RESS})^{15}$. Generally this process requires mainly consisting of preheated, solubilization vessel and precipitator. Firstly the heated gas becomes pressurized that containing solute and pumped into solubilization unit. Supercritical fluid dissolves solute is passed through heated nozzle, and then that solution becomes rapidly expanded at supersonic speed. Rapid expansion of supercritical solution in which both density and solvent power decreases it leads to solute supersaturating. The main advantage of RESS technique that produces the production of small particles with uniform size ${ }^{16}$.

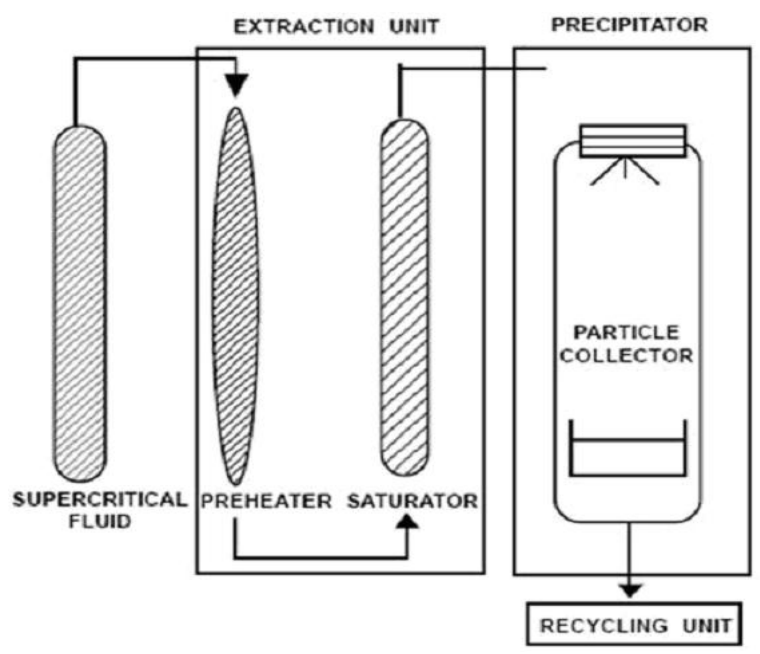

Figure 1: RESS (Rapid Expansion of Supercritical Solution)

2. RESOLV (Rapid expansion of a supercritical solution into liquid solvent):

Firstly the solution of the drug is dissolved in the liquid carbon dioxide inside a high-pressure syringe pump and the solution is pumped into a heating unit to attain the desired temperature conditions before expansion through a laser-drilled orifice and rapid solution occurs into the aqueous medium at ambient temperature ${ }^{9,17}$.

Technologies using SCF as an anti-solvent:

The supercritical fluid used as anti-solvent that comes in contact with the solute dissolved in a suitable organic solvent.

\section{Precipitation using SCF as an anti-solvent:}

$>$ A liquid solubilizes to a large amount of gaseous carbon dioxide.

$>$ Anti-solvent should have the low affinity for the solute but least partial miscibility with the organic phase.

$>$ Nucleation and the consequent growth of crystals from the solute /organic/anti-solvent system is governed by:

1. The diffusion of the anti-solvent into the organic phase.

2. The evaporation of the organic solvent into the antisolvent Phase ${ }^{9}$.

Different experimental designs of the anti-solvent processes which can be classified on the basis of different mixing modes between the solution and the SCF are:

\section{GAS (Gaseous Anti-solvent):}

\section{Advantages:}

The main advantages of this technique are to be introduced the SCF through the bottom of the vessel when a mixing of good solvent and anti-solvent can be obtained $^{9}$. 
$>$ It is a technique that involves the gradual introduction of carbon dioxide inside a vessel filled with the solute solution.

$>$ The carbon dioxide is pumped into the vessel till the fixed pressure is attained.

\section{PCA (particles by compressed anti-solvent),}

\section{SAS (Supercritical Anti-solvent), ASES (Aerosol Solvent Extraction System):}

$>$ In these three technologies the carbon dioxide used as supercritical fluid for SAS or PCA is firstly pumped into the high pressure vessel until the system reaches the desired conditions at that temperature and pressure. Then the organic solution is sprayed through nozzle into the SCF bulk and the particles are collected on a filter at the bottom of vessel.

\section{ASES (Aerosol Solvent Extraction System):}

It represents the modification implying the simultaneous spraying of the solution and anti-solvent.

\section{SEDS (Solution Enhanced Dispersion by Supercritical Solvent):}

It is an innovative technique developed by HANNA \& YORK $^{18}$.

$>$ In this process the drug solution and the supercritical fluids are introduced simultaneously into the particle formation vessel through the mixing chamber of a co-axial nozzle.

$>$ The use of the mixing chamber favors the higher mixing surface area that may leads to the increase the mass transfer. Then higher the mass transfer causes:

\section{A fast nucleation rate.}

2. The particles are formed of small size with little aggregation.

These are highly controlled, reproducible Technique as compared to another anti-solvent SCF processes and proved to be a suitable for scaling up and manufacturing according to the GMP requirements ${ }^{19}$.

Certain examples of Pharmaceutical compounds micronized and converted in amorphous form using SCF based techniques.

\begin{tabular}{|l|l|l|l|}
\hline & & & Reference \\
\hline 5 fluorouracil & SEDS & Increases in the solubility as spherical particles are formed. & Chen A. et al., 2006 \\
\hline amoxicillin & SAS & Amorphous spherical particles of 0.2-1.6 $\mu \mathrm{m}$. & Kalogiannis C. e tal., 2005 \\
\hline Lysozyme & GAS & $\begin{array}{l}\text { Amorphous spherical particles, more or less agglomerated } \\
200-300 \mathrm{~nm} .\end{array}$ & Muhrer G. et al., 2003 \\
\hline
\end{tabular}

Applications of the Supercritical fluids technology:

1. Use of Micronization of the drugs:

The Supercritical anti-solvent technique has been successfully used for the particle size reduction of the drugs having low solubility in the supercritical fluid, like trypsin, catalase, methyl etc. Some of Drugs which have been micronized by using Supercritical fluid techniques 5- Fluorouracil, Lysozyme, Atorvastatin Calcium, Cyclosporine A.

2. Enhancement of solubility of the drugs:

Supercritical fluid technology, Especially Rapid expansion on supercritical solution technique has been used for the improvement of the solubility of water insoluble drugs. Some examples of drugs processed to enhance solubility of water insoluble drugs. ${ }^{20}$ Atenolol Aerosol based solvent extraction system, Phenytoin Gaseous anti-solvent crystallization, Felodipine Supercritical anti solvent system, Naproxen Rapid expansion Supercritical solution.

3. Use of SCF technology in Solid dispersion:

It provides the advantage for the preparation of solid dispersion dosage form free of the organic solvent in order to enhance the solubility of the poorly soluble drugs having poor solubility e.g. A
PEG 4000 based solid dispersion of carbamazepine in order to enhance the dissolution rate and extent ${ }^{21}$.

4. Drying at various stages in the Pharmaceutical operations:

Drying is the process of the removal of solvent from the bulk mass, which has to be achieved at different phases in the development and production of a pharmaceutical product. Supercritical drying provides the benefits of removal of the solvent without appearance of the distortion and shrinkage in the solid particle that arise due to the effects of surface tension. Technique is being used in the production of the "Aero gel" (material having lowest bulk density of porous solid) and drying of the delicate materials as biological samples for electron microscopy ${ }^{11}$.

\section{FUTURE PROSPECTS}

The focus of this technique that should be drawn on exploring the application of the supercritical fluid technology and to find the other potential prospects that can effect on Supercritical fluid as defined in the critical temperature and pressure conditions, while reduction in the expenditure of the scale up that should also be considered, in order to improve the acceptability of this technique in the small as well as large industrial applications. 


\section{CONCLUSIONS}

SCF based technology currently valid tools to control the crystal form of pharmaceuticals. It is clear that by appropriate regulation of the working conditions specific crystal form a material can be produced, so investigation of the effects of these factors that affects the various characteristics of the particle still deserves a respectful approach, which should be focused on the particle kinetics and thermodynamics leading the

\section{REFERENCES}

1. Dalvi PB, Gerange AB, Ingale PR, Solid dispersion: strategy to enhance solubility, Journal of Drug Delivery and Therapeutics, 2015; 5(2):20-28

2. Shah DP, Patel B, Shah C, Nanosuspension technology: A innovative slant for drug delivery system and permeability enhancer for poorly water soluble drugs, Journal of Drug Delivery and Therapeutics, 2015; 5(1):10-23

3. Asadujjaman MD, Mishuk AU, Novel approaches in lipid based drug delivery systems, Journal of Drug Delivery and Therapeutics, 2013; 3(4):124-130

4. Mundhe AV, Cocrystalization: an alternative approach for solid modification, Journal of Drug Delivery and Therapeutics, 2013; 3(4):166-172

5. Gupta RB. Supercritical fluid technology for particle engineering, In: Gupta RB, Kompella UB editpors. Nanoparticle technologies for drug delivery, Volume 159 in Drugs and Pharmaceutical Sciences, Marcel Dekker, Inc, 2006, p 53-84.

6. Misra A, Jinturkar K, Patel D, Lalani J, Chougule M. Recent advances in liposomal dry powder formulations: preparation and evaluation. Expert Opin Drug Delivery. 2009; 6:71-89.

7. Pasquali I, Bettini R. Are pharmaceutics reallygoing supercritical? Int J Pharm. 2008; 364:176-187.

8. Duarte ARC, Duarte CMM, editors. Current Trends of the Supercritical Fluid Technology in the Pharmaceutical, Nutraceutical and Food Processing Industries. Bentham Books. eISBN: 978-1-60805-046-8, 2009

9. Pasquali I, Bettini R, Giordano F. Supercritical fluid technologies: an innovative approach for manipulating the solid-state of pharmaceuticals. Adv Drug Deliv Rev. 2008; 60:399-410. occurrence of the precipitation from the supercritical fluid. Supercritical fluid technology have found unique applications in the production and processing of drug particles and is now considered to be an innovative and promising way to design and modify pharmaceutical substances. By proper adjustment of operating conditions (physical and chemical parameters) with specific crystal form can be generated, the use of SCF in the pharmaceutical field, which allows the significant industrial applications in the coming future.

10. Liu H, Pan WS, Zhou LL, Guo H. Supercritical fluid technology and its application in pharmaceutics. Acta pharmaceu Sinica. 2007; 41:1123-1129.

11. Bhardwaj. L, Sharma P.K., Visht S, Garg V.K., Kumar N A review on methodology and application of supercritical fluid technology in pharmaceutical industry. Der Pharmacia Sinica, 2010; 1 (3):183-194

12. Van Hees T, Piel G, Evrard B, Otte X, Thunus T, Delattre L. Application of supercritical carbon dioxide for the preparation of a piroxicam-beta-cyclodextrin inclusion compound. Pharm Res. 1999; 16(12):1864-1870.

13. Brunner G, In: Brunner G (ed.), Gas extraction. Steinkopff Darmstadt, Springer, New York, USA, 1994.

14. Gupta R.D, J Pharma Sci Res, 2008; 6 (2): 200-240

15. Krukonis V, Supercritical fluid nucleation of difficult to comminute solids, Proc. Annual Meeting AIChE, paper 140f, t-124, 1998 .

16. Philips, E.M., Stella. V.J. Rapid Expansion from supercritical solutions: application to pharmaceutical Processes, Int J. Pharm, 1993; 94:1-10.

17. Meziani M.J, Pathak P, Beachman F, Allard L.F., Sun Y.P. Nanoparticle Formation in rapid expansion of water- insupercritical carbon dioxide microemulsion into liquid solution, J. Supercritcal Fluids, 2001; 34:91-97.

18. Hanna .M, York P, WO95/01221, 1995.

19. York. P, Hanns. M, Shekunov Y.P., Humphreys, G.O. Microfine particles formation by SEDS (Solution enhanced Dispersion by Supercritical Fluids): scale up by design, Proc. Resp. Drug Delivery VI, 1998; 169-175.

20. Ker. J, Knez. S, Sen. P, Int J Pharm, 1999; 182, 1:33-39.

21. Moneghini M, Kikic I, Voinovich D, Perissutti B, FilipovicGrcic J, Int J Pharm., 2001; 222(1):129-138. 